В.Л. Шевченко, А.М. Турейчук, О.А. Лаптев

\title{
УПРАВЛІННЯ ЕКОЛОГІЧНОЮ БЕЗПЕКОЮ ЛАЗЕРНИХ СИСТЕМ ЗІ СКАНУВАННЯМ ПРОМЕНЮ У ВІДКРИТОМУ ПРОСТОРІ ЗА ДОПОМОГОЮ ЕЛЕКТРОМАГНІТНИХ ДЕФЛЕКТОРІВ
}

\section{Аналіз останніх досліджень і публікацій, виділення невирішених частин проблеми. Актуальність і постановка задачі}

В сучасних лазерних приладах часто використовуеться випромінювання у відкритому просторі $[1,2]:$ у вимірювачах дальності, лідарах, комунікаційних, шоу-системах, системах лазерної терапії, озброєння, воєнної техніки та інших. В залежності від загальної та питомої потужності це може створювати небезпеку поразки людей, тварин та інших об'ектів, які опинилися у зоні випромінювання. Для военної срери у прямий постановці, осліплююча лазерна зброя заборонена додатком до Женевської конвенції від 10.10 .1980 р. (протокол IV, прийнятий в Видне 13 жовтня 1995 року) [3]. Але існує низка пристроїв військово-технічного та цивільного призначення, які виконують сканування навколишнього простору лазерним випромінюванням та створюють небезпеку випадкової поразки людей. Тому питання управління безпекою лазерного випромінювання, що сканує у відкритому просторі, є актуальним.

Завдяки низької вартості у практиці широко використовуються електромагнітні сканери (дефлектори) [4], недоліком яких є нерівномірність розподілу енергії по поверхні освітлювання, а саме, суттеве (у 10-15 і більш разів) перевищення дози на межі діапазону у порівнянні з серединою та усередненими показниками діапазону сканування у цілому [2]. Може скластись ситуація, коли на більшості діапазону сканування, випромінювання не створюе небезпеки, але на дуже малих крайових ділянках така небезпека існуе. Це робить актуальним питання лазерної безпеки скануючого випромінювання в різних ділянках зони сканування.

Існуючі підходи звичайно базуються на аналізі статичних характеристик лазерного випромінювання без урахування динаміки його руху [5-6]. В кращому випадку пропонуеться розраховувати енергетичну експозицію окремих ділянок опромінення на підставі аналізу динаміки руху променю, але дальше цього рекомендації не йдуть.

Метою роботи є розробка та вдосконалення підходів до управління рівнем лазерної небезпеки випромінювання, яке скануеться у відкритому просторі за допомогою електромагнітних дефлекторів. Додатковою метою е дослідження техніко-економічних та соціально-економічних факторів лазерної небезпеки.

(c) В.Л. Шевченко, А.М. Турейчук, О.А. Лаптев, 2005 


\section{Викладення основного матеріалу}

Введемо позначення. $D_{x}$ - рівень небезпеки розповсюдження та застосування лазерних пристроїв, в залежності від дії фактору $x$ (окремо: $D_{M}$ - від вартості; $D_{V m}$ - від масогабаритних показників пристрою; $D_{J u}$ - від рівня юридичного регулювання видів діяльності пов'язаних з лазерними технологіями; $D_{p}$ - від потужності випромінювання); $M$ - вартість; $J u-$ рівень юридичного регулювання видів діяльності пов'язаних з лазерними технологіями (в умовних експертних балах); $P, P^{\prime}=P / S$ - потужність та питома потужність лазерного випромінювання; $S$ - площа освітлювання; $m$ - маса; $l_{x}, l_{y}, l_{z}$ - лінійні розміри за трьома висями; $V$ - обсяг; $V m=\sqrt{V^{2}+m^{2}+l_{x}^{2}+l_{y}^{2}+l_{z}^{2}}-$ узагальнена оцінка масогабаритних показників пристрою.

В [1], одними з основних факторів лазерної небезпеки визначені невелика ціна, яка обумовлюе доступність придбання лазерів та невеликі масогабаритні показники, яки спрощують несанкціоновані доставку та використання лазерів в місцях чутливих до впливу факторів екологічної небезпеки. Відповідні залежності можуть бути представлені за допомогою логістичних SL- функцій [7] $D_{M}(M)=S L_{M}(-M)$, $D_{V m}(V m)=S L_{V m}(-V m)$ (рис. 1a). Аналогічно можна представити залежність рівня лазерної небезпеки від рівня юридичного регулювання $D_{J u}(J u)=S L_{J u}(-J u)$. Залежність небезпеки від потужності випромінювання має експонентний характер $D_{P}(P)=a_{P} \cdot e^{c_{P} P}$ (рис. 1б), де $a_{P}, c_{P}$ - деякі коефіцієнти. Загальна залежність рівня лазерної небезпеки має вигляд

$$
\begin{gathered}
D=S L_{M}(-M) \cdot S L_{V m}(-V m) \cdot S L_{J u}(-J u) \cdot a_{P} \cdot e^{c_{P} P}, \\
S L_{x}(x)=\frac{a}{1+e^{-c \cdot(x-\Delta x)}},
\end{gathered}
$$

де $S L_{M}, S L_{V m}, S L_{J u}$ - SL- функції [7], $a, c, \Delta x$ - коефіціенти: $a$ - верхня межа зростання; $c=2 / T$ - позитивний коефіцієнт, що залежить від величини періоду $T ; \Delta x$ - зсув точки симетрії графіка вздовж вісі абсцис.
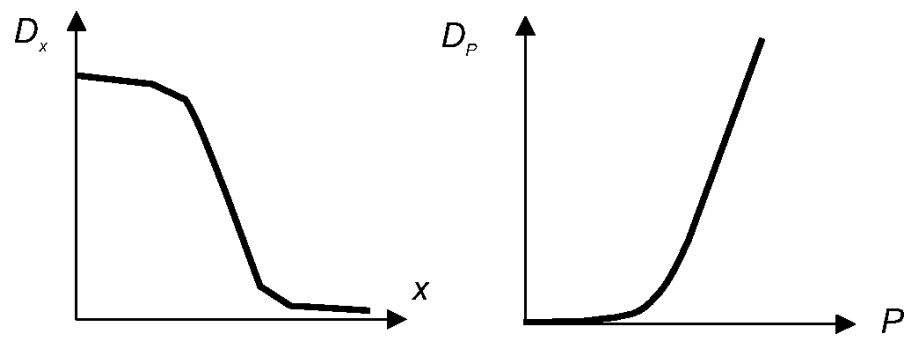

Рис. 1 - Рівні небезпеки розповсюдження та застосування лазерних пристроїв, в залежності від дії різних факторів.

При перспективному оцінюванні небезпеки лазерних технологій за допомогою (1), у першому наближенні, змінні $M, V m, J u, P$ можуть бути 
представлені деякими експонентними функціями часу. При аналізі рекомендуеться розглядати $J u$ як функцію часу незалежно від представлення інших змінних, $V m$ та $P$ представляти фрункціями часу якщо вважається $M=$ const, $M$ - представляти функцією часу, якщо $V m=$ const або $P=$ const.

В [8] запропонований спосіб забезпечення заданого рівня ефекту лазерної терапії, який у модифрікованому вигляді можна використати для управління рівнем лазерної безпеки скануючих лазерних систем сумісно з (1). Визначимо принципові відмінності постановки задачі даної роботи від [8]:

1. Небезпечним вважається навіть один окремий період сканування.

2. Мова йде про зворотну задачу, тобто недопущення перевищення деякого заданого рівня деструктивного ефекту замість забезпечення досягнення рівня корисного ефекту не менше завданого.

3. Оскільки випромінювання виконуеться у навколишньому просторі, то діаметр лазерної плями збільшуеться пропорційно відстані та відповідно зменшуеться питома потужність в зоні освічування зворотно пропорційно квадрату відстані.

Позначимо: $A$ - амплітуда вихідного сигналу, $\omega=2 \pi f$ - циклічна частота, $f$ - лінійна частота, $t$ - час, $E$ - енергія випромінювання, $r-$ радіус лазерної плями.

Звичайно, для управління електромагнітним дефлектором використовують синусоїдальний сигнал [2]. Завдяки динамічним властивостям дефлектору, навіть більшість несинусоїдальних вхідних сигналів перетворюється у наближений до синусоїдального вихідний сигнал. При фіксованої відстані до об'єкту випромінювання і малих кутах відхилення променю (4-10 град [2]) можна вважати лінійну амплітуду розгортки променю на поверхні освітлювання пропорційної куту відхилення. Тоді лінійне відхилення лазерної плями на поверхні освітлення $x$ та його похідна дорівнюватимуть

$$
x=A \sin \omega t, \frac{d x}{d t}=A \omega \cos \omega t=\omega \sqrt{A^{2}-x^{2}},
$$

Звісно, що

$$
P=\frac{d E}{d t} .
$$

В межах одного сеансу опромінювання можна вважати потужність випромінювання постійною. Тоді з $(2,3)$ запишемо залежність розподілу питомої енергії вздовж лінії розгортки та після відповідних перетворень отримаємо залежність розподілу енергії по поверхні освітлювання вздовж траєкторії сканування променю для чверті періоду сканування $E_{1 / 4}(x)$. 


$$
\begin{aligned}
& E(x)=P \int_{x-r}^{x^{\prime}} \frac{d x}{\omega \sqrt{A^{2}-x^{2}}}=\frac{P}{\omega} \arcsin \left(\frac{x}{A}\right) \mid \begin{array}{l}
x^{\prime} \\
x-r
\end{array}, \\
& x^{\prime}=\left\{\begin{array}{c}
x+r, \text { если } x+r<A \\
A, \quad \text { если } x+r \geq A
\end{array},\right. \\
& E_{1 / 4}(x)=\left\{\begin{array}{cl}
\frac{P}{\omega}\left(\arcsin \left(\frac{x+r}{A}\right)-\arcsin \left(\frac{x-r}{A}\right)\right), & \text { если } x+r<A, \\
\frac{P}{\omega}\left(\frac{\pi}{2}-\arcsin \left(\frac{x-r}{A}\right)\right), & \text { если } x+r \geq A,
\end{array},\right.
\end{aligned}
$$

Чисельне моделювання свідчить, що чім менш відношення $r / A$, тім більше нерівномірність розподілу енергії по поверхні (Рис. 2). Однократне освітлювання об’єкту включає експозицію при русі до межи діапазону сканування та зворотний рух (повернення), тоді вираз для освітлювання певної точки об'єкту на протязі одного періоду сканування прийме вигляд

$$
E(x)=2 \cdot E_{1 / 4}(x)
$$

В залежності від отриманої енергетичної дози [9] в організмі спочатку відбувається стимуляція обмінних процесів $D_{A}-D_{B}$, а при подальшому збільшенні - їх пригнічення $D_{B}-D_{F}$ (закон Арндта-Шульца) (Рис. 3). Закон Арндта-Шульца також зберігає свої якісні властивості, якщо в якості дози обирати різні енергетичні характеристики [2]: питому потужність [10-12], питому енергію [12, 13] або повну енергію [12], що поглинута організмом. Звичайно обирають повну поглинуту енергію (енергетична доза), з якою інші величини пов'язують шляхом відповідних перерахунків. Але, для розглянутої постановки задачі більш доцільно обрати питому енергію (7).

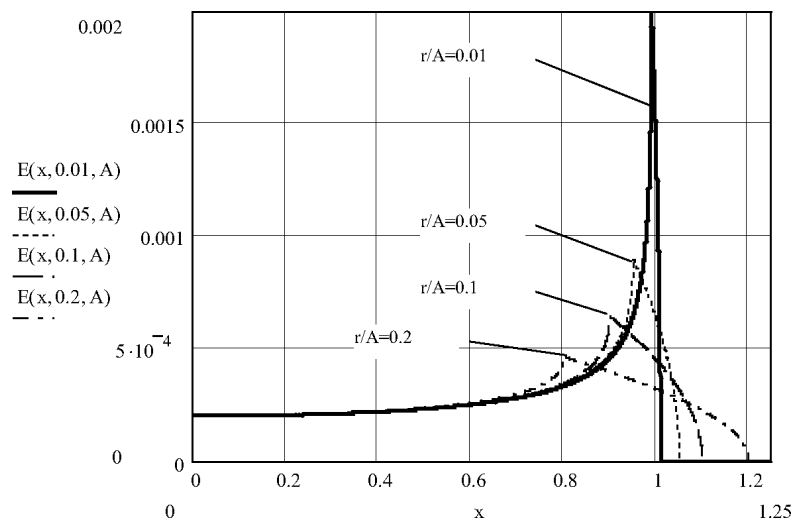

Рис. 2 - Розподіл енергії лазерного випромінювання по поверхні скануванHя. 
Повний ефект дії лазерного опромінювання складно виразити єдиним показником. Пропонуеться використовувати лінійну згортку оцінок за окремими показниками

$$
E f f_{\Sigma}(E)=\sum_{i=1, n} \beta_{i} \cdot E f f_{i}(E)
$$

де $\beta_{i}$ - ваговий коефіцієнт оцінки ефекту $E f f_{i}(E)$ по $i$-му параметру стану об'єкта. В подальшому розглядаємо лише результуючу залежність $E f f_{\Sigma}(E)$, яку будемо позначати $E f f(E)$, хоча всі міркування можуть бути узагальнені і на залежності окремих ефектів $E f f_{i}(E)$.

$$
E f f(E)=\int_{x_{0}}^{x_{1}} E f f_{x}(E) d x,
$$

де $E f f_{x}(E)$ - питома енергетична доза в точці $x ; x_{0}, x_{1}$ - координати меж діапазону для якого визначаеться сумарний ефект.

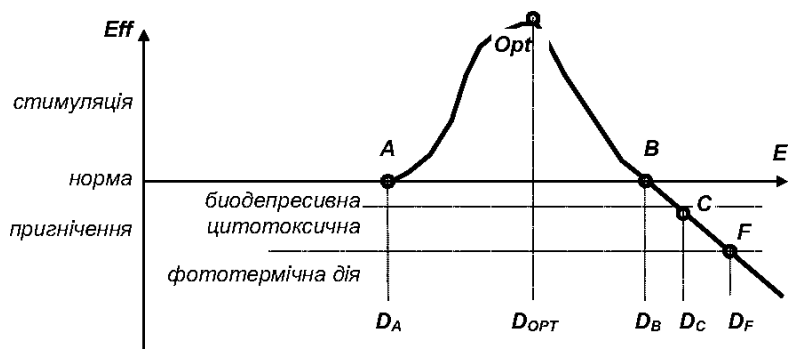

Рис. 3 - Залежність ефекту дії лазера на біологічний об’єкт від дози.

При побудові моделі найбільш точно мають бути завдані координати точок $E_{\min }, E_{\max }$ в яких $E f f_{x}(E)=0$. Залежність (Рис. 3) можна представити за допомогою певних логістичних SL- функцій [7] $S L_{1}, S L_{2}$ у вигляді

$$
E f f_{x}(E)=S L_{1}(E)-S L_{2}(E) d x
$$

Для спрощення аналітичних операцій з апроксимуючою залежністю (10) використаємо властивість похідної SL- функції та правило апроксимації добутку SL- функцій [7].

$$
\frac{d S L(E)}{d E}=c \cdot S L(E) \cdot(a-S L(E)) \approx c \cdot\left(S L_{1}(E)-S L_{2}(E)\right) .
$$

Для (7) виконаємо лінійну сплайн-інтерполяцію.

$$
E(x, r)=\sum_{i=1, n} d_{i}(r)+k_{i}(r) \cdot x,
$$

де $d_{i}(r), k_{i}(r)$ - коефріцієнти $i$ - го сплайн-відрізка. Тоді з урахуванням (10-12) представимо (9) у вигляді 


$$
\begin{aligned}
& E f f(r)=\sum_{i=1, n} k_{i}(r) \cdot \int_{E_{i-1}(r)}^{E_{i}(r)} \frac{d S L(E)}{d E} d E= \\
& =\sum_{i=1, n} k_{i}(r) \cdot\left(S L\left(E_{i}(r)\right)-S L\left(E_{i-1}(r)\right)\right) .
\end{aligned}
$$

Тепер задачу можна сформулювати як пошук множини таких значень параметру $r$, при яких забезпечуеться величина сумарного ефекту не більше деякого завданого рівня

$$
E f f(r) \leq E f f_{z a d} .
$$

За допомогою (13) будуемо графік $E f f(r)$, накладаемо обмеження (14) та знаходимо діапазон припустимих величин $r>r_{\min }$. Задача вирішуеться чисельно або графоаналітичним методом (рис. 4). На підставі інформації про відстань до об'єкту можна перерахувати обмеження на кут розходження променю, який вважаємо управлінням.

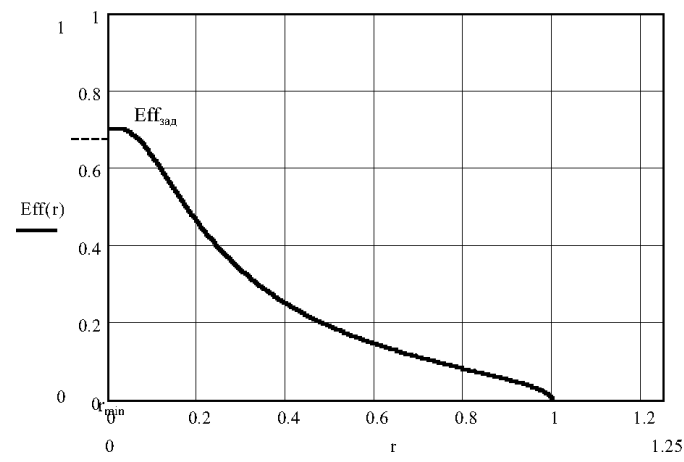

Рис. 4 - Залежність ефректу дії лазерного випромінювання від радіусу лазерної плями.

Загальний алгоритм забезпечення заданого рівня лазерної безпеки сорормулюемо наступним чином.

1. Завдати попередні вхідні дані: $r_{0}, r_{1}$ з урахуванням відстані до об'єкту та кута розходження променю; $E_{\min }, E_{\max }, E f f_{z a d}$ виходячи з інформації про потенційні об'єкти опромінювання; $f, A$ - виходячи з інформації про режими сканування.

2. 3 допомогою (7) побудувати допоміжний масив значень функції $E(x, r)$ для діапазону аргументів $r \in\left[r_{0}, r_{1}\right], r_{1} \leq A, x \in[0, A+r]$ с кроком, який забезпечуе 50-200 значень на діапазон.

3 . На підставі масиву $E(x, r)$ побудувати масиви інтерполюючіх коефіцієнтів $k_{i}(r)$ і координат меж сплайн-відрізков $E_{i}(r)$. Для забезпечення необхідної точності, в залежності від величини $r$, достатньо розраховувати 15-50 відрізків інтерполяції.

4. За допомогою (13) будуемо $E f f(r)$. 
5. Визначаємо параметри апроксимуючої SL-функції

$$
\Delta E=\frac{E_{\max }+E_{\min }}{2}, \quad T=\Delta E-E_{\min } .
$$

6. 3 урахуванням (15) чисельним або графооналітичним способом знаходимо діапазон припустимих величин $r>r_{\min }$.

\section{Висновки}

Таким чином у роботі запропонований загальний підхід щодо управління екологічною безпекою скануючих лазерів. Проаналізовані окремі техніко-економічні та соціально-економічні аспекти лазерної безпеки. Розроблена методика та запропонований алгоритм управління рівнем екологічної безпеки скануючих лазерів, які побудовані на основі електромагнітних дефлекторів.

Якщо, для завданих умов та обмежень застосування скануючих лазерних систем не вдаеться знайти рішення, що задовольняє умовам постановки задачі, то рекомендуеться заміняти електромагнітні дефлектори на дефлектори які не мають ефекту крайового передозування, наприклад акустооптичні. Але слід врахувати, що така заміна призводе до суттевого збільшення вартості.

Напрямками подальших досліджень мають бути поширення запропонованої методики на інші типи дефлекторів, поглиблення досліджень щодо техніко-економічних та соціально-економічних аспектів лазерної безпеки.

\section{Література}

1. Шевченко В.Л. Современная лазерная техника как источник лазерной опасности// в журн. "Арсенал XXI століття", 2, 2002. - с.21

2. Шевченко В.Л. Основы рационального применения терапевтических лазеров.- Киев: НПО “Профрессор”, 2003. - с. 170

3. Право війни: Порадник для командного складу Збройних Сил України / Під загальною редакцією В.П.Базова. -Видання друге, доповнене - Київ: “Поліграфкнига", 1997. - с. 112

4. Ребрин Ю.К. Управление оптическим лучом в пространстве. М.: "Советское радио", 1977. - с. 336

5. Санитарные нормы и правила устройства и эксплуатации лазеров 5804-91.- М.: Изд.дом "Имидж", 1991. - с. 95

6. Справочник по лазерной технике. Пер. с нем. - М.: Энергоатомиздат, 1991. - с. 544.: ил.

7. Шевченко В.Л. Использование SL-зависимостей для построения моделей развития технологий и упрощения процедур поиска оптимальних решений на примере уравнения Беллмана // Системні технології. Регіональний міжвузівський збірник наукових праць. - Випуск. 6 (35). - Дніпропетровськ: ДНВП "Системні технології", 2004. - С.148153. 
8. Спосіб забезпечення заданого рівня ефекту лазерної терапії. Пат. 6524, Україна, МПК 7 А61Н5/06. В.Л.Шевченко. - Заявка 200500483. Заявлено 18.01.05. Опубл. 2005, Бюл. 6. - 4c., ил.

9. Михайлов В.А., Скобелкин О.К., Денисов И.Н. Основные принципы низкоинтенсивной лазерной терапии для лечения онкологических больных в запущенной стадии заболевания // Перспективные направления лазерной медицины (Материалы международной конференции г. Одесса 18-20 ноября 1992 г.) Москва, Одесса, 1992. - С.341344.

10. Илларионов В.Е. Лазерная терапия // Врач. - 1992 8, с.11-16.

11. ИНСТРУКЦИЯ по применению лазерной физиотерапевтической установки УФЛ-01 для лечения стоматологических заболеваний // Типовая инструкция по охране труда при проведении работ с лазерными аппаратами. М.:1988. - С. 6-15.

12. Корепанов В.И. Теория и практика лазерной терапии. Часть первая. М.: НПП "Рапид", 1993. - с. 110

13. Лобода М.В., Самосюк І.З., Колесник Е.О. Нетрадиційні та фрізіотерапевтичні методи лікування в АТ „Укрпрофоздоровниця” // Медицинская реабилитация, курортология, фризиотерапия. - 1998. - 1(13). - C.3-5. 